\title{
DOI: 10.7596/taksad.v8i3.2209
}

Citation: Vusyk, H., Oliynyk, E., \& Pavlyk, N. (2019). The Problem of Linguistic Integration: The Social and Linguistic Adaptation of Refugees in the Modern International Space. Journal of History Culture and Art Research, 8(3), 220-233. doi:http://dx.doi.org/10.7596/taksad.v8i3.2209

\section{The Problem of Linguistic Integration: The Social and Linguistic Adaptation of Refugees in the Modern International Space}

\author{
Hanna Vusyk ${ }^{1}$, Elina Oliynyk ${ }^{2}$, Nelia Pavlyk ${ }^{3}$
}

\begin{abstract}
The problem of forced migration is one of the most difficult in today's world space in general and on the European continent in particular, and it requires an integrated approach from the international community to solve this issue. Statistics show that the number of displaced persons in 2018 reached almost 71 million people. Ukraine experiences the problems of migration heavily too. The recent military conflict has forced the inhabitants of Donetsk and Luhansk regions to seek asylum in the other safe parts of the country. Besides, Ukraine's labor migration is rapidly increasing. Millions of Ukrainians live permanently outside of Ukraine. On the other hand, thousands seek asylum from Ukraine. The accumulated international and actual Ukrainian experience suggests that the main problems faced by displaced persons are: a) the question of their legal status in the host territories; b) humanitarian needs (access to education, medical services, social security, etc.), c) official employment, d) psychological and social adaptation, e) negative informational policy, which leads to possible discrimination on national, cultural and other grounds, religion, etc. f) hope only for state financial assistance as the main source of existence, etc. It is especially worth emphasizing that one of the most important aspects of legal and social adaptation of refugees is their interpersonal communication and direct interaction with representatives of state bodies for assistance to refugees, executive authorities, other authorities, public associations, and local people, which is an important element of support and integration of displaced persons. Thus, the priority component of the migration policy of any state is linguistic integration as one of the resources of the socio-cultural adaptation of refugees. Within the framework of the proposed article, we focus on understanding the problems of the language integration of forced displaced persons in the modern international space, promoting the development of speech interaction as the main means of migrants entering the local community, forming socio-communicative competence - a compulsory component of a successful communicative process that also educates the respectful attitude of refugees towards the traditions of the host community.
\end{abstract}

Keywords: Forced displaced persons, Refugees, Migration policy, Linguistic integration, Socio-linguistic adaptation, Socio-communicative competence.

\footnotetext{
${ }^{1} \mathrm{PhD}$ in Philology, Associate Professor of The Department of Ukrainian Language and Slavic Studies, Berdyansk State Pedagogical University, Faculty of Philology and Social Communications, Ukraine.

Correspondence E-mail: hanna.vusyk@gmail.com

${ }^{2} \mathrm{PhD}$ in Philology, Associate Professor of The Department of Ukrainian Language and Slavic Studies, Berdyansk State Pedagogical University, Faculty of Philology and Social Communications, Ukraine.

Correspondence E-mail: hanna.vusyk@gmail.com

${ }^{3} \mathrm{PhD}$ in Philology, Associate Professor of The Department of Ukrainian Language and Slavic Studies, Berdyansk State Pedagogical University, Faculty of Philology and Social Communications, Ukraine.

Correspondence E-mail: hanna.vusyk@gmail.com
} 


\section{Introduction}

The problem of forced migration requires an integrated approach to provide solutions: on the one hand, the identification of ways to prevent mass forced displacement of persons and the emergence of new flows of refugees, and on the other - identification of legal and humanitarian resources for their effective social integration and adaptation in new living conditions. The reasons for becoming a refugee are commonly known: military-political and ethnic conflicts, socio-economic crises, political persecution, natural disasters (the so-called ecological migration) make people look for a better life in a foreign country, and today these processes have become the global international problem. The annual report of the Office of the United Nations High Commissioner for Refugees "Global Trends" (June 20, 2019) states that the number of displaced persons in 2018 reached a record number of 70.8 million people.

The migration processes also happen in Ukraine, in particular, the following trends are observed: firstly, the internal forced migration: the military conflict that has arisen in the East of our country in 2014 and has not been resolved to this day, has forced the inhabitants of Donetsk and Luhansk regions to seek asylum in the other safe parts of the country - as of September 13, 2018, the Ministry of Social Policy of Ukraine (2018) registered 1 million 518 thousand internally displaced persons; secondly, migration to Ukraine: Ukraine is a transit territory through which the migration flows to Western European countries are taking place (today Ukraine has adopted 2620 refugees and persons who have received additional protection; 6500 asylum seekers are waiting for the results of consideration of their applications for asylum) (the UN Refugee Agency, 2019); thirdly, migration from Ukraine (in particular, labor migration): due to the difficult socio-economic situation in the country caused by the war in Donbass and not good economic policy of the state's leadership, Ukraine's labor migration is rapidly increasing. In December 2018, according to the official data of the State Migration Service and the State Border Service, 3 million 200 thousand citizens work permanently outside Ukraine, and the volatile figure ranges from 7 to 9 million Ukrainians (Ukrinform, 2018).

Nowadays, because of the importance of the forced displacement of persons' issue, migration processes are considered as a separate scientific field, based on a comprehensive approach to the study of refugee issues in the contemporary international space. It is quite reasonable to emphasize the multidisciplinary nature of the topic (Zhvanko, 2015), whose analysis requires a set of tools in various scientific fields, namely: law, international law, sociology, history, demography, economics, social activity, linguistics, etc. Priority areas for the research on IDPs and refugees are:

- Legal regulation of refugee status in international and national practice. It should be emphasized that the rights of refugees are a separate area of international law; in this respect, the legal acts which determine the status of refugees and internally displaced persons are carefully examined, and the legal and regulatory activities of the relevant international and regional authorities to protect internally displaced persons are directed. The international legal instruments that formulated and formalized the refugee status are the Refugee Convention (1951) and the Refugee Status Protocol (1967). In addition, the Office of the High Commissioner for Refugees operates under the auspices of the United Nations. Ukraine acceded to the Convention and Protocol on January 10, 2002, and the refugee status has been granted in our country since 1996 in accordance with the Agreement between the Government of Ukraine and UNHCR. An important step in the protection of the refugees' rights was the adoption on 8 July 2011 of the Law of Ukraine "On Refugees and Persons in Need of Additional or Temporary Protection". However, despite the large number of legislative documents governing the legal basis for refugee protection and assistance, researchers point out that the legal regulation of the status 
of designated categories of persons requires recommendations on how to improve the provisions in force and develop new acts to take into account the realities of today and counter new threats that refugees and internally displaced persons face (Syroid, 2017: 155).

- Social adaptation of internally displaced persons and refugees. In the broad sense of the problem, scientists underline the emergence of a new branch of sociology - the sociology of migration, the object of which is the migration process as a social interaction of the population, which is included in the socio-geographical movement, and the subject - the objective and subjective aspects of displaced persons' social relationships within the limits of the previous and the new society (Yudina, 2004: 90; Zaionchkovskaia, Molodykova, \& Mukomelia, 2007: 267).

- The process of social adaptation is an important component of migration policy and involves a structured system of social support for refugees, with a scientifically shaped legal framework and practical implementation. In particular, the study of the experience of the US, Canada, and other countries have allowed scientists to identify the main areas of social assistance for refugees: social (providing temporary asylum); socio-pedagogical (development and implementation of comprehensive rehabilitation programs for language, culture, education, vocational training, psychological and pedagogical counseling); social and legal (promotion of legal entry into the country, legal advice); financial (financial assistance); social and labor (assistance in professional self-determination, mastering the profession, employment); socio-information (providing information on education and health care); medical and social (Olkhovich, 2008: 9-10); social and psychological (primarily to overcome the consequences of absolute and relative social deprivation and isolation), etc.

- The refugee problem in historical perspective. The history of refugees has been studied quite actively - from ancient times to the present; the scientific literature also covers the creation of a global system of international protection for internally displaced persons. According to experts, the study of the historical experience, in particular, the causes of this phenomenon, will help to find the tools to overcome the migration crisis that has arisen in the world in recent years.

- Socio-economic consequences of migration processes. In science, there is a concept of economic migration, which is interpreted as a change of place of residence through the search for work and which is associated with the increasing globalization processes in the world economy. Scientific interest is raised by the question of importance of migration processes in general and of refugees in particular for national economies, namely, the impact of migration on economic development, unemployment rate, changes in employment, public expenditures on the placement of displaced persons and their social adaptation, etc. (Zaionchkovskaia, Molodykova, \& Mukomelia, 2007: 361-317). The theoretical understanding of key aspects of economic migration and the development of effective methods of its regulation at the state and interstate levels are relevant.

- Migration processes in the socio-cultural dimension. Scientific understanding of the essence of migration is impossible without studying the socio-cultural component of this phenomenon, which involves the analysis of intercultural relationships and the development of strategies for the formation of the most acceptable model of a new multicultural society. Migration is related to the process of acculturation - the interaction and interplay of different socio-cultural systems, the whole or partial perception of another community culture. At the base of any adaptation - legal, socio-cultural, economic, social, etc. lies the communicative process, linguistic and language skills that allow one to live fully and act in any linguosocium. The issue of socio-linguistic adaptation in the context of migration policy and work with refugees needs special attention, in particular, the development of 
theoretical, methodological and practical mechanisms for the socio-communicative competence formation and the solution of migrants' problems.

These directions emphasize the multidimensionality and globality of the selected issues, so the methods of their solution must be diverse - from prevention to ensuring repatriation (return to the Motherland) or successful integration into the local community.

\section{Methodology}

The theoretical and methodological basis of the study is an interdisciplinary and integrated approach to the analysis of the problem of forced migration in the modern world space, based on the application of the scientific knowledge theory; philosophical provisions on the interconnection and interdependence of the objective reality phenomena; basic methodological principles of science, objectivity, systematicity, social conditionality, interrelation of theory and practice; studies by foreign and Ukrainian scholars on the theory of migration problems, including the research for ways to overcome the crisis of forced displacement. The information base of the research is international and national legislative acts on the regulation of migration processes and work with refugees; statistical calculations; results of sociological surveys, questionnaires, interviews, etc. Besides, works in the fields of law, political science, history, sociology, economics, cultural studies, linguistics in the context of migration and refugee problems; methodical and regulatory documents on the identified issues, materials from the Internet, journalism, etc. are used.

The concept of our research assumes that there are interconnected concepts that contribute to the leading idea's realization:

1. The methodological concept that involves the selection and interaction of fundamental scientific ideas and approaches to the study of problems that were the base during the research. The ideas of implementing a policy of language integration of refugees under the conditions of humanization and human-centrism are fundamental, which determine the axiological aspect of the study, confirm the self-worth of the individual in the process of socio-linguistic adaptation. The theory of migration and migration policy are important for the study, the studies on refugee problems as a social phenomenon and the evolution of the "refugee" concept, study of integration and its typology in the aspect of migration processes, the position of language philosophy, theory of language contacts, studies on language situation and language policy, theory of communication, theory of intercultural communication.

2. The theoretical component that defines the basic concepts, theories, ideas, provisions, definitions that determine the understanding of the process of refugees' linguistic integration, specific tasks, principles, content, methods of socio-communicative competence formation as a mechanism for successful adaptation of IDPs.

3. The technological concept implies the development of theoretical-methodological and practical mechanisms for socio-linguistic adaptation in the context of migration policy and work with refugees, taking into account the principles of respect for human rights, equality, non-discrimination, etc.

In the course of the research, a complex of methods of scientific research was used, in particular: interpreter-analytical method, on the basis of which Ukrainian and foreign sources were studied; method 
of theoretical generalization that contributed to the formulation of generalized conclusions and the substantiation of practical recommendations; method of historical analysis was used to describe migration processes in historical dynamics; sociological method - during the research of refugee rights problems' realization, their socio-linguistic adaptation; sociolinguistic methods and techniques, in particular, method of linguistic interpretation and comparative analysis of the objective and subjective characteristics of migrants' speech behavior.

The study followed the methodological principles of: objectivity (which promotes a comprehensive analysis of the socio-linguistic aspect of migration processes and the basic principles of the society's language policy towards refugees and foresees the exclusion of subjectivism, unilateralism, and bias in the selection and evaluation of the studied phenomena); essential analysis (correlation of the phenomena of external, special and single in the studied phenomena, penetration into their internal structure, disclosure of application and functioning conditions as well as factors of development, possibilities of their purposeful change); logical and historical (a combination of studying the history of an object (genetic aspect), of theory (structure, functions, relationships of the object in its present state), prospects); conceptual unity of the study (explaining the phenomenon under study, based on understanding of the nature and patterns of socio-linguistic adaptation and linguistic integration of refugees).

\section{Background}

The study of scientific works on the outlined problem has shown that the issues of the history of refugee emergence in the world space and the evolution of the concept of "refugee" are in the spotlight of both Ukrainian and foreign researchers. The legal regulation of the status of designated categories of persons today is in dire need of developing recommendations on improving existing provisions and developing new documents that take into account current realities and counter new threats to refugees.

Refugees as a social phenomenon have been accompanying humanity since ancient times. The wars of the Middle Ages and modern times caused the forced migration of the population in Europe and beyond. Most American colonists in the seventeenth century were originally from England, who left the country after the bourgeois revolution. The Thirty Years War in the Austrian Empire, the revolutionary events in Europe in the 1820s and 1840s also contributed to a significant increase in refugee flows in the 19th century. The Russian Empire received a large number of asylum seekers from the countries under the Ottoman Empire. However, in the twentieth century, since the outbreak of World War I, the refugee status has become unprecedented in Europe. Over the centuries, its forms have changed and the definition has become broader (Piskorski, 2010: 24).

A review of the literature indicates that during the 20th-21st centuries there are at least nine waves of emigration in Europe caused by various factors: World War I (1914-1918); the inter-war upheavals (1920-1930); World War II (1939-1956); "Cold War" (1950-1960); the African flow (the 1960s); the Yugoslav script (1992-1997); the post-Soviet space (1990s-2000s); "hybrid war" in Ukraine (2010s); and Syrian crisis (2010s) (Zhvanko, 2015).

Turning to the historical aspect gives reason to claim that only in the early twentieth century due to the significant increase in the number of asylum-seekers and the increased respect for human rights, the problem of refugees became international, which eventually led to the creation of international profile structures. 
Thus, in the 1920-30s, the League of Nations (the precursor of the United Nations), the first international body for intergovernmental cooperation to launch refugee assistance in Europe, was created. It was the Council of the League of Nations that organized and held the Geneva Refugee Conference in 1928, which laid the foundation for the formation of the legal framework for the global system of international refugee protection. This problem remains a priority on the agenda of the first session of the United Nations General Assembly (UN) in 1946.

In 1947, the United Nations established the International Refugee Organization (IRO), the first institution to comprehensively address all aspects of international refugee protection (registration, status, transfer, legal and political protection, etc.), and the Office of the United Nations High Commissioner for Refugees (UNHCR) was created in 1949 as a subsidiary body of the General Assembly. It was under the auspices of the United Nations that the States adopted the Refugee Convention in 1951, which is the main international legal instrument that regulates the status of refugees and protects their rights and freedoms. In 1967, the Protocol on the Status of Refugees was developed for the said Convention, which significantly expanded its scope and provided new opportunities.

A number of important international legal instruments for the protection of the rights of refugees have been adopted within the international community: the International Convention on the Protection of the Rights of All Migrant Workers and Members of Their Families (in 1990), the Declaration of the High-Level Dialogue on International Migration and Development (in 2013), the New York Declaration for Refugees and Migrants (in 2016).

The modern definition of the term "refugee" is formulated within the framework of international and national systems of law. This term has been repeatedly transformed by the influences of new trends in migration processes and the reasons that cause the emergence of numerous flows of refugees.

The first definitions of this concept appear in various special treaties and conventions adopted by the League of Nations in 1926-1938 and relate to the status of refugees. These interpretations provided a very simple system of criteria that made it possible to distinguish more clearly between refugees and persons who left their country of origin solely for personal reasons. The group or categorical approach was used in which the appropriate nationality and lack of protection by the government of the original country were sufficient conditions for recognizing the person as a refugee. This division into categories was simple and made it easy to identify who a refugee was. It should be noted that not all the agreements of the League of Nations required the staying of a person outside the country of origin, although this condition was foreseen. The purpose of these agreements was to permit the issuance of identity cards that would provide travel and resettlement.

The peculiarity of these definitions relies on why a person is forced to leave his/her country of origin, in particular, the consequences of the First World War, the change of political structure in many countries, the religious contradictions of some Asian countries and so on. Undoubtedly, the behavior of states contributed to the creation of critical situations that resulted in the flow of refugees, and therefore this problem became political since the destiny of such citizens depends on the attitude of the state.

In elaborating legal acts adopted by the international community concerning the regulation of the rights of refugees, we see the attempts to involve the political aspect in the term "refugee". For example, in 1938 the Institute of International Law in its resolution recognized as refugees persons who had to leave their country of origin for reasons of their political beliefs, religion and race, which 
subsequently had a great influence on the formation of the international legal definition of the term (Collection, 2000: 19-41).

The analysis of the agreements made by the League of Nations allows outlining the provisions that have underpinned modern definitions. One such trend was the gradual narrowing of the term "refugee" within the specific legal criteria that supplemented that definition with an indication of the reasons why the person left the country of his or her nationality or residence. Such interpretations are found in the documents adopted after the Second World War. In particular, the Constitution of the International Refugee Organization (in 1948), the term "refugee" refers to persons who left or remained outside the country of their nationality or permanent residence and belonged to the following groups: victims of Nazi or fascist regimes recognized as hostile during World War II, whether or not they had international refugee status; victims of the Falangist regime in Spain, whether or not they had international refugee status; persons recognized as refugees before the Second World War on the grounds of race, religion, nationality or political beliefs; orphans under the age of 16 whose parents died outside their country of origin (Potyrała, 2015: 115).

The UNHCR Charter of 1950 identifies two categories of civilians who can be considered as refugees: 1) persons who have already obtained refugee status under previous international agreements, or persons who have grounds to apply for refugee status as a result of events that had occurred by 1 January 1951 and 2) persons who are outside the country of their nationality or the country of residence, fearing persecution on the basis of their race, religion, nationality, political views, and at the same time unable or do not want to enjoy the protection of the state's government (UNHCR Charter, 1950).

The provisions of the 1951 Convention Relating to the Status of Refugees provide a generalized interpretation of the term "refugee" - a person who, as a result of events occurring in his or her country, has reason to fear persecution on the basis of race, religion, nationality, political view, affiliation with certain social groups outside the country of which he or she is a citizen and who is unable or unwilling to claim the protection of that country due to his / her fears (Convention, 1951).

Taking into consideration the increasing urgency of the refugee problem, the Protocol was adopted in 1967 to clarify the notion of "refugee", abolishing temporal and geographical constraints, and extending the 1951 Convention to all participating states. In addition, all the states ensured to cooperate with the United Nations specially designated body, the Office of the High Commissioner for Refugees, and to provide him/her with information on the state of refugees, refugee legislation, and data on the implementation of the 1951 Convention.

The beginning of the formation of refugee legislation in Ukraine dates back to the first years of independence. Thus, in 1996, an agreement was concluded between the Government of Ukraine and the Office of the United Nations High Commissioner for Refugees, which sets out the conditions for cooperation between these structures.

It is worth noting that the legislation on the legal status of refugees in Ukraine took place in several stages, each of which was marked by a rapid accumulation of regulatory material and detailing the provisions of the adopted laws: "On Refugees" 1993, 2001; "On Immigration" 2001; on "Citizenship of Ukraine" 2001; "On Refugees and Persons in Need of Additional or Temporary Protection" in 2011. The last law introduced the subsidiary protection institutions for the first time: additional and temporary as well as created conditions for granting protection to foreigners and stateless persons who did not satisfy the criteria of the term "refugee", but for whom there were circumstances of impossibility of expulsion outside Ukraine, besides the procedure for applications' considering for recognition him or 
her as a refugee or a person in need of extra protection is clearly outlined, basic guarantees for the rights of refugees and persons in need of additional protection in terms of documentation, social protection, health care, education, etc. are established.

An important step in defining the term "refugee" in the Ukrainian legislation was the approval by the Cabinet of Ministers of Ukraine of the "Plan of measures for the integration of refugees and persons in need of additional protection into the Ukrainian society for the period up to 2020" in 2012, which narrowed down and maximum approximated it to the 1951 Refugee Convention (CMU Ordinance, 2012).

Based on the analysis of the current legislation of Ukraine, it can be stated that a serious basis was created for the further gradual development of conditions favorable to refugees in our country, and also made it possible to distinguish between the terms "refugee", "forced displaced persons (displaced persons)", "persons in need of additional protection", "persons in need of temporary protection":

a) a refugee is a person who is not a citizen of Ukraine; is outside the country of origin, may or may not wish to enjoy the protection of that country; is justifiably afraid of becoming a victim of persecution on the basis of race, religion, nationality, citizenship, membership of a particular social group or political beliefs; cannot or will not return to it because of these fears;

b) forced displaced persons or displaced persons are persons who have left a particular conflict region of a state and settled in another region within that state;

c) persons in need of temporary protection are persons who are not refugees under the 1951 Convention; were forced to come or stay in Ukraine; need protection as a result of threats to life, safety or freedom in their country of origin, for fear of the death penalty or the execution of a death sentence or torture, inhuman or degrading treatment or punishment;

d) persons in need of temporary protection are foreigners and stateless persons who reside permanently on the territory of the country sharing a border with Ukraine; massively forced to seek protection in Ukraine; need protection because of the threats of external aggression, foreign occupation, civil war, ethnic clashes, natural or man-made disasters, or other events that disturb public order in some parts or in the whole country of origin (Law of Ukraine, 2011).

We also pay attention to the concept of "asylum seeker". According to the definition given by the Office of the United Nations High Commissioner for Refugees (UNHCR), an asylum seeker is a person who has left his or her country of origin and has applied for refugee status in another country and is awaiting a response. According to them, asylum seekers are the most vulnerable category of displaced persons (UNHCRM).

Examining the sources for the formation and development of refugee law, we can say that the above concepts, due to changes in the causes of their emergence, the increasing number of homeless people, have significantly transformed and acquired new features.

\section{Sociolinguistic problems}

The term integration has various interpretations in the scientific literature. In sociology, integration is understood as the process of establishing optimal relations between relatively independent social objects (individuals, groups, social classes, states) and their subsequent transformation into a single, coherent system in which their interdependent parts are coordinated, based on common goals and interests; involvement of persons with disabilities in society as full members of it, who take an active 
part in all spheres of life (Sociology, 1998). The Oxford University Dictionary considers integration as "the act or process of combining two or more parts so that they function together" (Oxford Advanced, 2000: 675). Integration processes occur both within a system that is already created, which increases its integrity and organization, and when a new system is created from the previously unrelated elements.

Migration professionals view integration as a dynamic, consistent implementation of policies aimed at active measures to learn the new language of society, its traditions, culture and values, and access to the labor market and social support (IOM, 2014). It is important to emphasize that the integration of migrants is a mutual process aimed at the assimilation and survival of migrants in the host society, which can contribute to the economic and demographic development of the society itself (Iontsev, 2014).

O. Rinzak (2014), summarizing the scientific studies on this issue, identifies three groups of models of migrants' integration into the host society: liberal, communitarian (collectivist) and relational. In a liberal concept, an individual is recognized as the most important social unit, and the basis of such a society is the equality of individuals, which implies equal rights (voting and freedom of speech) and duties (the need to obey the law and not violate the rights of other citizens). The opposite is the liberal communitarian model, which has three directions of development:

a) assimilation, the essence of which is that migrants must abandon their customs, traditions, and instead accept the norms and values of the host society - learn the language, adapt to the lifestyle of the majority, etc.;

b) the so-called alloy model means that migrants do not have to dissolve into the values of the dominant majority, but to integrate into them in order to facilitate the formation of new cultural patterns;

c) multiculturalism means the preservation of migrants' own culture, along with the culture of the majority; they take an active part in the economic and political life of the host society and have the right to develop their own language, to keep customs, and so on.

The following model - relational - provides an integrated society with a high degree of social interaction and participation; the purpose of state integration policy is to develop and implement measures to integrate migrants into society without requiring their assimilation. The essence of the relational model is social equality, cultural diversity, political unity (Rinzak, 2014: 72-75). The researchers identify two types of integration: full integration, which involves the assimilation of migrants, and partial integration based on adaptation to new conditions.

The integration of refugees into the host country consists of learning the language, norms, social roles, customs of the country. The language itself is one of the defining means of integration: if the refugee can speak and understand the language of the host community, the opportunities for integration are greatly increased. Learning the country's national language is one of the priorities that should be available at an early stage in the integration process.

The nature of society can be considered as the criterion of language integration:

- the ability of society to regulate the language situation independently;

- the ability of society to effectively control the activities of the competent authorities on language issues;

- the coherence and predictability of the speech behavior of social members in critical situations on the path of democratization. 
The study identified factors that affect the language acquisition of the host country:

- Native language. The problems that arise in learning a language depend on the typological similarities and differences that exist between the mother tongue and the target language. The process is complicated when the target language differs from the mother tongue or another already learned language.

- The previous level of education. Many refugees come from countries with fragile infrastructure, with extreme poverty, war. This means that many of them were unable to attend school and could not acquire basic knowledge even in their native language.

- The cultural environment of the original country. If some refugees are connected by a cultural space (for example, the post-Soviet one), then the situation is quite the opposite for refugee categories with an unfamiliar cultural environment.

- Ethics. European education, behavior, and expectations often differ from the cultural norms of refugees' countries of origin. Such a category of people may need assistance in adopting new habits and adapting to them (for example, it is customary to praise listeners among Slavs, while representatives of some cultures feel uncomfortable; too close a glance while visual contact may be perceived as an insult; tactile contacts are invalid, etc.).

- Physical health is an important factor in language acquisition. This is especially true for older refugees: many of them have hearing and vision impairments, which reduce the ability to perceive educational material.

- Mental health. Depression is common among refugees. They survived a war, disorder, separation from their homeland, their loved ones. Depression is also exacerbated by the fact that refugees, not knowing the language, customs of the host country, are not able to solve basic everyday problems.

- Social identity, or self-reproduction. Not having the lowest social status in the homeland, in another country a refugee can often claim only the lowest social levels.

When we talk about the integration of refugees into the society of the host country, we should not forget about the process of acculturation, which can sometimes be a barrier to integration.

It is found that the factors that reduce the level of motivation in learning a language are:

- Social isolation. In order to learn a new language, one has to speak it as often as possible when speaking to its native speakers. The impossibility of full socialization leads to a decrease in motivation in the process of mastering the language.

- Changing family roles. Children who learn the language, as a rule, are more likely to become family coordinators, explaining situations to adults, and helping to meet communication needs.

The main features of language integration capabilities are identified, namely:

- formation of an appropriate linguosocium based on processes of national and cultural identity;

- regulation and design of cultural (including ethno-linguistic) processes and their support. 
Integration function in society can be performed only by a language, which is officially recognized as a language of international communication within a country. The result of the process of linguistic integration should be a common communication space for the country.

\section{Socio-communicative competence}

Contemporary research offers different definitions of communicative competence. It is considered as:

- the level of formation of interpersonal experience necessary for an individual to function successfully in a certain society within the limits of his/her abilities and social status;

- a person's ability to communicate as a complex multicomponent dynamic holistic speech activity that can be influenced by various factors;

- the ability to coordinate the interaction of its individual components to ensure the effectiveness and efficiency of communication.

The results of familiarization with the scientific literature and the analysis of the above definitions of communicative competence enabled us to form our understanding of this concept in the context of the proposed research.

Communicative competence is defined by us as the ability of a person to understand and reproduce the language of the host state in accordance with the various goals and specificities of the communication situation.

Based on the structure of communicative competence proposed by B. Bloom, G. Mados, and J. Hastings (the UN Refugee Agency, 2019), we distinguish:

1) discursive competence (the ability to combine individual sentences into a coherent oral or written message);

2) sociolinguistic competence (the ability to understand the context and perform the function of influencing the interlocutor);

3) strategic competence (the ability to be effectively engaged in communication by choosing the right discourse strategy);

4) linguistic competence (the ability to understand and produce learned or similar statements, as well as the potential to understand new, unstudied statements).

\section{Social and language adaptation}

In our opinion, communication in society is fundamental and is one of the most important components of a successful and self-sufficient personality. Therefore, in our study, we view adaptation as a holistic, systemic process that characterizes human interaction with the social environment. As the term socio-cultural adaptation is known to science, the concept of socio-linguistic adaptation clearly exists, too. Moreover, the two terminological combinations are closely interrelated.

Under socio-linguistic adaptation, it is appropriate to understand the process of accumulation of active and passive vocabulary, which ensures the transfer of information for the purpose of successful verbal communication for refugees from other countries. We regard it as advisable to consider this form of adaptation at the phonetic, lexical, grammatical and stylistic levels. The result of socio-linguistic 
adaptation, in our view, should be the complete linguistic relationship of a migrant with a language that he/she does not perceive as foreign. However, successful language adaptation is impossible in a society isolated from native speakers.

Therefore, the concept of language adaptation at different times remains one of the most interesting phenomena, as it is dynamic and debatable. It should be noted that migrants' adaptation processes, in particular, their socio-linguistic adaptation, are determined by the individual's psychological characteristics, level of personal development, behavior, as well as age, the purpose of migration, type of activity, etc., all of which provide prospects for further research.

\section{Conclusion}

The research revealed that the global integration processes of the modern world are an objective trend in the development of all spheres of public life. They have included the culture, the spiritual life, the educational sphere, becoming the determining factors for shaping the way and quality of life of the whole world. Refugees are the most socially disadvantaged part of the population of any state. As a rule, IDPs come from their home country alone or in small groups and cannot rely on their government that is the main factor for them to be different from other migrants and groups in need of social assistance. Europe pays considerable attention to the problems of refugees and annually shelters tens of thousands of asylum seekers. In Ukraine, on the other hand, the unstable economic situation, legislative inconsistencies and corruption, xenophobia, and shortcomings in the national asylum system are hindering the successful integration of refugees.

In our study, we raised the issue of forced migration, which is one of the most difficult in the world today and analyzed the international and Ukrainian experience of linguistic integration of refugees. The authors substantiate the concepts of "refugee" and "asylum seeker", describe the problems of refugees they face in the new conditions of life. Work with sources on the formation and development of refugee law suggests that the above concepts have substantially transformed and acquired new outlines. The authors of the article traced the history of refugees' migration.

We conclude that learning the host country's national language is a priority and should be accessible at an early stage in the integration process. Socio-linguistic problems include language integration, socio-communicative competence, and socio-linguistic adaptation. The result of linguistic integration must be a common communication space for the country, which is important for adaptation as a coherent, systemic process that characterizes human interaction with the social environment. According to the authors, socio-linguistic adaptation implies the free use of language in the process of interaction in society.

The proposed article provides an impetus for further studies of EU migration policy; developing a strategy to address the current situation in European countries as a result of the influx of refugees from Eastern and other countries.

\section{References}

Charter of the Office of the United Nations High Commissioner for Refugees, 14 December 1950 (1950). URL: http://zakon2.rada.gov.ua/laws/show/995_277

CMU Ordinance dated August 22, 2012, № 605 "Approving a Plan of Measures to Integrate Refugees and Persons in Need of Additional Protection into Ukrainian Society for the Period up to 2020". (2012). URL: http://zakon2.rada.gov.ua/laws/show/605-2012-\%D1\%80 
Convention on Refugee Status (1966). URL: http://zakon3.rada.gov.ua/laws/show/995_011.

Convention on the Status of Refugees Arriving from Germany, February 10, 1938 (2000). Collection of International Legal Documents and National legislation on Refugee Issues. Minsk.

Iontsev, V. A. (2014). Integration of Migrants is an Effective Way to Eliminate Inequality and Xenophobia in the Host Society. Management Issues, 17, 127-132. URL: https://cyberleninka.ru/article/v/integratsiya-migrantov-effektivnyy-put-ustraneniya-neravenstva-iksenofobii-v-prinimayuschem-obschestve.

Law of Ukraine dated July 08, 2011. № 3671-VI “About Refugees and Persons in Need of Additional or Temporary Protection" (2011). URL: http://zakon5.rada.gov.ua/laws/show/3671-17.

Olkhovich, O. V. (2008). Training Social Workers to Work with Refugees in the US and Canadian Institutions of Higher Education: Ph.D. thesis: 13.00.04 - Theory and Methods of Professional Education. Ternopil.

Oxford Advanced Learner's Dictionary of Current English (6 ${ }^{\text {th }}$ ed.) (2000). Sally Wehmeier (Ed.). Oxford.

Piskorski, J. M. (2010). Exiles. Resettlement and Refugees in 20th Century Europe. Warsaw.

Potyrala, A. (2015). United Nations and the Refugee Problem: The Origin, Essence, and Practice of Activity. Warsaw.

Research on Integration, Hate Crimes and Discrimination Against Different Categories of Migrants (2014). Kyiv. URL: http://iom.org.ua/sites/default/files/study_0.pdf.

Rinzak, O. T. (2014). Policy Models for the Integration of Migrants into the Host Society. Economy and State, 1, 72-75. URL: http://www.economy.in.ua/pdf/11_2014/17.pdf

Social Protection of Internally Displaced Persons (2018). URL: https://www.msp.gov.ua/news/15904.html.

Sociology. A Short Encyclopedic Dictionary (1998). V. Volovych (Ed.). Kyiv. URL: https://www.turkaramamotoru.com/uk/Соціальна-інтеграція-216151.html.

Syroid, T. L. (2017). International Legal Basis for Regulating the Status of Refugees and Internally Displaced Persons: Realities and Prospects. Bulletin of the V. N. Karazin Kharkiv National University. The Law Series, 154-157.

The UN Refugee Agency (2019). 2019 World Refugee Day. URL: https://www.unhcr.org/ua/16067всесвітній-день-біженців-2019.html

Ukrinform (2018). Reva said how many Ukrainians earn their bread abroad. URL: https://www.ukrinform.ua/rubric-society/2606697-reva-zaavlae-so-zarobitcan-uze-ponad-12miljoniv.html

UNHCR's Global Trends Annual Report Shows the Highest Level of Forced Displacement in the World (2019). URL: https://www.unhcr.org/ua/15808-увкб-оон-опублікувало-щорічний-звіт-п.html.

UNHCRM: Protecting Refugees with Questions and Answers (2013). URL: http://unhcr.org.ua/uk/khtomi-dopomagaemo/bizhentsi/102-zahystbizhentsiv-u-zapytannyakh-ta-vidpovidiakh.

Vusyk, H. L. (2012). The Influence of the Social Environment on Language and Speech Behavior. Theoretical and Applied Problems of Russian Philology, 23, 271-275. Slaviansk.

Vusyk, A. L. (2008). The Formation of the Cultural and Linguistic Individual Competence. Actual Problems of Slavic Philology: Linguistics and Literary Knowledge, 16, 63-70. Kyiv. 
Yudina, T. N. (2004). Sociology of Migration: Towards the Formation of a New Scientific direction. Moscow.

Zaionchkovskaia, Zh., Molodykova, I., \& Mukomelia, V. (2007). Methodology and Methods for Studying Migration Processes: An Interdisciplinary Study Guide. Moscow.

Zhvanko, L. M. (2015). Refugees on the European Continent: Humanitarian Challenges. Security, Political, Economic and Humanitarian Dimensions of the Current Stage of European Integration and Euro-Atlantic Integration of Ukraine (pp. 181-184). Uzhhorod. 